\title{
KORELASI KEHIDUPAN BERISLAM MASYARAKAT DESA BARUGA DENGAN KEMAKMURAN, KEAMANAN DAN KETENTRAMAN HIDUP
}

\author{
Mukran H. Usman \\ Sekolah Tinggi Ilmu Islam dan Bahasa Arab (STIBA) Makassar \\ mukran@stiba.ac.id \\ Aswar \\ Sekolah Tinggi Ilmu Islam dan Bahasa Arab (STIBA) Makassar \\ aswar@stiba.ac.id
}

\begin{abstract}
Abstrak
Kehidupan berislam masyarakat Desa Baruga Kecamatan Bantimurung Kabupaten Maros tampak begitu nyata. Hal ini bisa dilihat dari beberapa hal, di antaranya adalah keberadaan masjid di semua dusun yang ada. Aktivitas salat berjemaah yang rutin terlihat di masjid-masjid tersebut dan keberadaan kegiatan taklim pekanan magrib isya di beberapa masjid. Dalam kondisi keberislaman yang nyata tersebut, warga muslim Desa Baruga juga bisa dikatakan sebagai masyarakat yang memiliki kehidupan yang makmur dengan indikator sebagai desa swasembada. Desa yang aman tentram dengan indikator Desa Baruga dikatakan sebagai desa religius. Penelitian ini bertujuan untuk mendeskripsikan bagaimana korelasi kehidupan berislam masyarakat Desa Baruga dengan kondisi kehidupan yang makmur, aman dan tentram. Metode penelitian yang digunakan adalah penelitian deskriptif kualitatif dengan pendekatan yuridis normatif, sosiologis dan fenomenologis. Hasil penelitian menunjukkan bahwa terdapat implikasi kehidupan berislam masyarakat Desa Baruga dengan kehidupan masyarakat yang makmur, aman dan tentram. Ihwal tersebut tampak dari hasil pertanian yang baik yang mencukupi kebutuhan keluarga (masyarakat), tingkat kejahatan yang kurang, dan eratnya hubungan persaudaraan di antara warga masyarakat Desa Baruga.
\end{abstract}

Kata Kunci: Korelasi, Desa Baruga, Makmur, Aman, Tentram. 


\begin{abstract}
The Islamic life of the people of Baruga Village, Bantimurung District, Maros Regency seems very real. This can be seen from several things, including the existence of mosques in all hamlets. Congregational prayer activities are routinely seen in the mosques and the existence of evening prayer meetings in several mosques. In the real Islamic conditions, Muslim citizens of Baruga Village can also be said to be people who have a prosperous life with indicators as self-sufficient villages. A peaceful village with indicators of Baruga Village is said to be a religious village. This study aims to describe how the correlation between the Islamic life of the people of Baruga Village with prosperous, safe and peaceful living conditions. The research method used was descriptive qualitative research with normative, sociological and phenomenological juridical approaches. The results showed that there were implications of the Islamic life of Baruga Village people with a prosperous, safe and peaceful life. This is evident from the good agricultural yields that meet the needs of the family (community), the level of crime that is lacking, and the close relationship between the residents of the Baruga Village community.
\end{abstract}

Keywords: Correlation, Baruga Village, Prosperous, Safe, Peaceful.

\title{
PENDAHULUAN
}

Kehidupan yang makmur, aman dan tentram adalah nikmat dan karunia yang melebihi nilai kemewahan dunia beserta isinya. Dalam hadis Nabi Shallallahu 'Alaihi Wasallam, beliau bersabda yang artinya: "Seorang muslim yang pagi harinya dalam keadaan badan yang sehat, tentram hatinya, dan ia memiliki makanan yang cukup untuknya pada hari tersebut maka seolah dia telah mendapatkan dunia beserta isinya."1 Ketika kondisi seorang muslim dalam keadaan yang makmur, aman dan tentram maka kondisi tersebut akan berpengaruh pada baiknya keadaan keluarga dan masyarakat. Seorang yang makmur kehidupannya maka akan berpeluang membantu saudaranya yang mengalami kesulitan, demikian pula seorang yang aman dari berbagai keburukan dan orang yang hidup tentram maka keduanya akan memberikan peran untuk kemaslahatan dan kebaikan masyarakat.

Salah satu tempat yang masih cukup alami untuk melakukan pembinaan nilainilai keislaman adalah lingkungan pedesaan. Dari sejak zaman Nabi Shallallahu 'Alaihi Wasallam sampai sekarang, ${ }^{2}$ lingkungan desa masih memiliki peran yang besar dalam menciptakan kehidupan yang Islami. Dari desa-lah lahir ulama dan

\footnotetext{
${ }^{1}$ Ibnu Ma>jah abu Abdillah ibn Yazi>d al-Qazawaini>, Sunan Ibnu Ma>jah, Juz 2 (Cet. t.d; Mesir: Da>r Ihya' al-Kutub al-Arabi>, t.th), h. 1387

${ }^{2}$ Sofiyurrahma $>$ n al-Muba $>$ rak al-Fu>ri, Al-Rohi $>q$ al-Makhtu>m (Cet. 1; Beirut: Da>r al-Hila>1, t.th), h. 46
} 
umara bangsa melalui pondok-pondok pesantren, ${ }^{3}$ dari desa-lah masyarakat kota bisa mendapatkan sandang pangan. Antara desa dan Islam sangat erat hubungannya, nilainilai Islam untuk mencapai pada kehidupan yang makmur, aman dan tentram masih begitu sangat dirasakan. Bahkan, dalam al-Qur'an, Allah Ta'ala mengambil permisalan keimanan dari permisalan keimanan penduduk desa (qoryatun). Allah Ta'ala berfirman dalam Q.S. al-A'raf/7: 96,

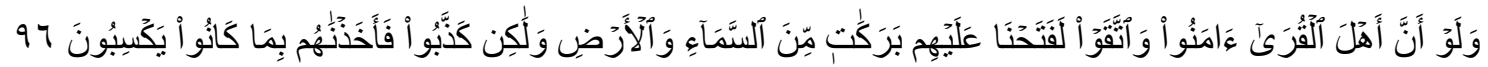

Artinya:

"Jikalau sekiranya penduduk qoryatun (desa) beriman dan bertakwa, pastilah Kami akan melimpahkan kepada mereka berkah dari langit dan bumi, tetapi mereka mendustakan (ayat-ayat Kami) itu, Maka Kami siksa mereka disebabkan perbuatannya."

Ukhuwah masyarakat desa juga masih begitu kental, saling bergotong royong dalam pekerjaan, kehidupan yang sederhana, serta penghormatan kepada orang tua, ${ }^{4}$ adalah sebagian contoh dari keberadaan nilai-nilai Islam pada masyarakat pedesaan. Oleh karena latar tersebutlah yang mengantarkan penulis tertarik mengkaji salah satu masyarakat desa di Sulawesi Selatan, tepatnya di Desa Baruga yang berada pada Kecamatan Bantimurung Kabupaten Maros. Ihwal yang hendak dikaji tentang bagaimana hidupnya nilai-nilai Islam warga Desa Baruga yang kemudian memberikan pengaruh pada kemakmuran, keamanan dan ketentraman. Desa Baruga yang penulis lihat-amati cenderung memiliki kehidupan yang makmur, aman dan tentram dengan kehidupan keIslaman warga yang baik. Hal tersebutlah yang menjadi alasan dan keinginan yang kuat untuk kemudian mengkaji korelasi kehidupan berislam dengan kondisi kehidupan yang baik pada warga Desa Baruga. Adapun fenomena ini terlihat tatkala penulis dimandatkan sebagai dosen pembimbing lapangan (DPL) mahasiswa KKN STIBA Makassar angkatan III dengan lokasi penempatan di Desa Baruga.

Untuk penelitian sebelumnya, penulis tidak menemukan jurnal ilmiah, buku referensi atau tulisan ilmiah yang membahas khusus tentang korelasi kehidupan berislam masyarakat Desa Baruga dengan kehidupan yang makmur, aman dan tentram di desa tersebut. Namun, ada beberapa penelitian yang memiliki relevansi dengan apa yang penulis kaji dalam artikel ini, di antaranya adalah:

1. Penelitian yang dilakukan oleh Ali Imran dengan judul "Peranan Agama Dalam Perubahan Sosial Masyarakat." Dalam penelitiannya, beliau menyimpulkan bahwa agama memiliki peran dan pengaruh yang besar untuk perubahan kehidupan masyarakat, di antaranya dalam kehidupan sosial, pendidikan dan

${ }^{3}$ Ahmad Ready dan Aliva Riwana, "Peran Pesantren Dalam Dunia Pendidikan Islam di Indonesia", https://www.academia.edu/39477169/PERAN_PESANTREN_DALAM_DUNIA_PENDIDIKAN_ISLAM_DI INDONESIA (2019)

${ }^{4}$ Riska, dkk., Masyarakat Pedesaan dan Masyrakat perkotaan (Jakarta: Universitas Indraprasta PGRI, 2007), h. 11.

${ }^{5}$ Ali Imran, "Peranan Agama Dalam Perubahan Sosial Masyarakat”, Hikmah 2, no. 1 (2015): h. 25-26. 
ekonomi. Penelitian ini tentu sangat membantu artikel ini, walaupun tidak membahas beberapa hal yang penulis kaji, termasuk dalam hal ini adalah lokus penelitian atau tempat yang menjadi bahan penelitian penulis yaitu Desa Baruga.

2. Penelitian yang dilakukan oleh Mukhlis Aliyudin dengan judul "Pengembangan Masyarakat Islam dalam Sistem Dakwah Islamiyah."6 Dalam penelitian beliau yang memiliki relevansi dengan apa yang penulis kaji dalam artikel ini, bahwa kehidupan berislam dengan landasan dakwah Islamiyah akan memberikan perubahan dalam kehidupan bermasyarakat.

3. Penelitian yang dilakukan oleh Muhamad Takhim dengan judul "Sistem Ekonomi Islam dan Kesejehteraan Masyarakat."7 Dalam penelitiannya, beliau menjelaskan bahwa sistem Islam yang termasuk di dalamnya adalah sistem ekonomi Islam sangat memberikan pengaruh pada kesejahteraan hidup manusia.

Masih ada beberapa penelitian yang memiliki relevansi dengan penelitian yang penulis kaji dalam artikel ini, namun penelitian-penelitian tersebut tidak mengkaji tempat dan masyarakat yang penulis kaji. Perbedaan juga tampak dari tujuan yang ingin penulis kaji sebagai sebuah karya ilmiah yang bisa memberikan pengetahuan dan wawasan lebih luas tentang korelasi kehidupan berislam masyarakat Desa Baruga dengan kehidupan yang aman, makmur dan sejahtera. Dengan segala keterbatasan sumber pustaka ilmiah, penulis tetap berusaha untuk bisa melanjutkan penelitian ini dengan bersandar kepada Allah Ta'ala dan kemudian dengan bantuan dari warga yang sempat kami wawancarai untuk pengambilan data.

\section{METODOLOGI PENELITIAN}

Metode penelitian yang digunakan adalah pendekatan deskriptif kualitatif. Pengumpulan data primer secara langsung dengan mengambil data dan informasi dari lapangan dengan melakukan beberapa bentuk wawancara yang kemudian diolah menjadi bahan dan rujukan penelitian ini. Kemudian, penulis menjadikan data sekunder berupa artikel jurnal, tesis, skripi, dan buku-buku ilmiah sebagai data penting dalam pengolahan penelitian ini, yang kemudian diolah menjadi bahan yang utuh. Selain itu juga, bahan primer dari al-Qur'an dan hadis-hadis Rasulullah Shallallahu 'Alaihi Wasallam sebagai dasar utama pengembangan dan penguatan secara ilmiah dalam penelitian ini. Penelitian ini juga mengaplikasikan beberapa metode pendekatan seperti pendekatan sosiologis, pendekatan historis dan pendekatan fenomenalogis dalam menganalisis, memperkuat dan memperkaya bahan primer dan bahan sekunder serta menyimpulkan hasil penelitian.

\footnotetext{
${ }^{6}$ Mukhlis Aliyudin, "Pengembangan Masyarakat Islam Dalam Sistem Dakwah Islamiyah", Jurnal Ilmu Dakwah 4, no. 14 (2009): h, 785.

${ }^{7}$ Muhamad Takhim, "Sistem Ekonomi Islam Dan Kesejahteraan Masyarakat", Jurnal Islam dan Sosial 10, no. 4 (2016): h, 84
} 


\section{PEMBAHASAN}

Banyak tempat yang kadang luput atau bahkan tidak ada perhatian kita tentang kehidupan berislam di tempat tersebut yang sebenarnya bisa menjadi contoh dan tauladan bagi masyarakat muslim di tempat lain. Belajar dan ilmu itu tidak terbatas pada lembaran-lembaran buku yang dibaca, tidak terbatas pada ruang-ruang perpustakaan yang luas atau pada majelis-majelis ilmu di masjid dan musala. Namun, ada tempat yang sebenarnya kaya akan ilmu dan nilai, yaitu sejarah dan budayanya, tidak lain masyarakat beserta desa tempat tinggal dan hidup mereka. Adapun salah satu desa yang kaya akan pelajaran dan ilmu, Islam dan nilainya yaitu Desa Baruga yang berada di Sulawesi Selatan, Kabupaten Maros, Kecamatan Bantimurung. Desa baruga yang masyarakatnya mayoritas muslim hidup dalam suasana yang makmur, aman dan tentram, menjadi dasar utama untuk mengulas, menelaah dan mengkaji kehidupan kesehariannya.

\section{A. Kehidupan Berislam Masyarakat Desa Baruga}

\section{Sejarah Islam di Desa Baruga}

Desa Baruga Kecamatan Bantimurung adalah satu wilayah yang berada dalam Kabupaten Maros yang mayoritas penduduk aslinya adalah muslim (pemeluk Islam). Keberadaan Islam di Maros sudah cukup lama yaitu dengan masuk Islamnya Raja Gowa-Tallo yang memiliki wilayah perbatasan langsung dengan Kerajaan Marusu Maros tepatnya pada malam Jumat 9 Jumadil Awal 1014 H., atau bertepatan dengan tanggal 22 september $1605 \mathrm{M}^{8}$ Sejarah Islam di Maros juga dikuatkan dengan keberadaan beberapa bukti akan keberadaan Islam beserta penyebarannya di Maros. Di antaranya adalah keberadaan makam-makam tua yang ada di Maros seperti makam Mattako yang terletak di kampung Bonto Biraeng, Desa Bonto Manai, Kecamatan Marusu, Kabupaten Maros dengan terdapat sekitar 50 makam muslim tua (pekuburan Islam) yang juga di dalam makam ini terdapat Makam Petta Lapalloso yang sudah ada sejak tahun 1700 M. ${ }^{9}$ Bukti yang lain berupa keberadaan Masjid Turikale yang diyakini pembangunannya pada tahun 1854 oleh Raja Turikale ke IV. ${ }^{10}$

\section{Nahdatul Ulama (NU) di Desa Baruga}

Nahdatul Ulama yang lebih dikenal dengan sebutan NU yang Lahir pada 31 Januari 1926, ${ }^{11}$ adalah termasuk organisasi Islam yang besar di Indonesia dan sangat memberikan pengaruh pada penanaman nilai-nilai keislaman pada masyarakat Desa Baruga Maros. Kehadiran dakwah NU di Desa Baruga dalam beberapa bentuk

\footnotetext{
${ }^{8}$ Jumadi, “Institusi Sara' di Maros Sulawesi Selatan”, Attoriolong 7, no. 2 (2010): h, 36.

${ }^{9}$ Rosmawati, "Makam-Makam Kuno Sebagai Bukti Tamadun Islam di Kabupaten Maros Sulawesi Selatan", (2017): h, 7-9.

${ }^{10}$ Mulyadi dan Muhammad Nur, "Ragam Hias Pada Makam di Komplek Mesjid Makam Turikale di Maros Sulawesi Selatan”, Kalpataru 26, no. 1 (2017): h. 27.

${ }^{11}$ Amin Farih, "Nahdatul Ulama (NU) dan Kontribusinya Dalam Memperjuangkan Kemerdekaan dan Mempertahankan Negara Kesatuan Republik Indonesia (NKRI)”, Walisongo 24, no. 2 (2016), h. 252 
kegiatan, seperti kedatangan para dai-dai dari pesantren DDI Mangkoso Barru, ${ }^{12}$ yang merupakan salah satu pesantren yang berada dibawa organisasi Islam NU untuk berdakwah dalam bentuk khotbah Jumat ataupun pengajian dan taklim. Bapak hasir, ${ }^{13}$ seorang warga di Dusun Samariga Desa Baruga menyampaikan bahwa beliau sangat dekat dengan ustaz-ustaz dari pesantren DDI Mangkoso Barru karena mereka sering datang untuk mengisi kajian dan khotbah Jumat di kampung halamannya.

\section{Desa Baruga dan Dakwah Kahar Muzakkar ${ }^{14}$}

Islam yang telah ada di Maros sejak tahun $1700 \mathrm{M}$ tentu menjadi tempat yang sangat strategis dalam penyebaran dan penegakan Islam di wilayah Sulawesi Selatan. Maros juga menjadi basis yang sangat strategis untuk membangun kekuatan Islam yang berorientasi gerakan jemaah oleh para tokoh-tokoh Islam seperti Abdul kahar Muzakkar. ${ }^{15}$ Tokoh yang sempat memproklamasikan Sulawesi Selatan dan sekitarnya sebagai bagian negara Islam Indonesia pada tanggal 7 agustus $1953 .{ }^{16}$ Dari hasil wawancara penulis pada salah seorang Imam masjid di Dusun Samariga yaitu bapak haji Kamaruddin, ${ }^{17}$ beliau mengatakan bahwa Desa Baruga adalah salah satu desa yang menjadi tempat keberadaan pengikut dari Abdul Kahar Muzakar dengan corak dakwah Islamnya yang sampai saat ini keberadaan dan pengaruh dakwah itu masih ada, terutama di tiga dusun Desa Baruga yaitu Dusun Samariga, Dusun Cambajawa dan Dusun Balang yang dikenal sebagai dusun yang sangat kental nilai-nilai Islaminya. Pengaruh dakwah Abdul Kahar Muzakar di Desa Baruga sampai sekarang masih terasa, hal tersebut dikuatkan dengan pernyataan bapak Hasir, ${ }^{18}$ seorang mantan kepala Desa Baruga yang menyampaikan bahwa Abdul Aziz Kahar Muzakkar ${ }^{19}$ yang merupakan anak dari Abdul Kahar Muzakkar sering datang ke Dusun Samariga dan mengisi pengajian di Masjid Miftahussalam Samariga.

\section{B. Dakwah Islam di Desa Baruga}

Dakwah Islam pada realitanya terbagi menjadi 2 (dua), yaitu dakwah umum dan dakwah khusus. ${ }^{20}$ Penyebaran Islam yang terjadi di Sulawesi Selatan termasuk di dalamnya Desa Baruga Maros juga melalui 2 (dua) metode dakwah tersebut. Kesadaran warga Desa Baruga untuk hidup dengan nilai-nilai Islami yang merupakan

${ }^{12}$ DDI adalah Singkatan dari Darul Dakwah wa al-Irsyad yang di dirikan oleh Annagurutta KH. Samad 1928 di Sengkang Wajo yang kemudian dikembangkan oleh murid beliau Gurutta Abdurrahman Ambo Dalle yang kemudian mendirikan DDI mangkoso.

${ }^{13}$ Hasir (51 Thn), Petani, Dusun Samariga, Wawancara 28 februari 2020, Pukul 11.30 WITA.

${ }^{14}$ Asma Nur, "Maros Pada Masa DI/TII 1953-1965", Skripsi (Makassar: IPS Kekhususan UNM Makassar, 2015), h. 6.

${ }^{15}$ Lahir di Lanipa, Pinrang Selatan, Luwu,Sulawesi Selatan,24 maret 1921, Meninggal di lasolo, Sulawesi Tenggara, 3 februari 1965.

${ }^{16}$ Nur Aisyah, Patahuddin, dan H.M. Rasyid Ridha, "Baraka: Basis Pertahanan DI/TII di Sulawesi Selatan (1953-1965)", Pattingalloang 5, no. 2 (2018): h. 58.

${ }^{17}$ Haji Kamaruddin (65 Thn), Petani dan imam masjid miftahus salam Samariga, Wawancara 24 Feb 2020, 14.30 WITA

${ }^{18}$ Hasir (51 Thn), Petani, Dusun Samariga, Wawancara 28 Februari 2020, Pukul 11.30 WITA.

${ }^{19}$ Politisi, Senator, Anggota DPD RI Sulawesi Selatan 3 periode dan dikenal sebagai salah satu keturunan dari Abdul kahar Muzakkar.

${ }^{20}$ Syabuddin Gede dan Abdul Ghafar Hj Don, "Model Dakwah: Satu Analisis Teoritikal", Ulum Islamiyah 16 (2015), h. 25-29. 
agama leluhur warga dengan giatnya, sangat terasa kegiatan dakwah melalui dua metode dakwah tersebut. Dari hasil wawancara dengan bapak kepala Desa Baruga yaitu bapak Muhammad Ilyas ${ }^{21}$ bahwa pemerintah beserta warga terbuka menerima dakwah dari organisasi dakwah dari luar desa, termasuk dari Wahdah Islamiyah ${ }^{22}$ melalui Sekolah Tinggi Ilmu Islam dan Bahasa Arab (STIBA) Makassar yang sejak tahun 2018 sampai tahun 2020 telah memilih Desa Baruga sebagai tempat penempatan mahasiswa melaksanakan kuliah kerja nyata (KKN) sebagai bentuk pengabdian kepada Masyarakat. Demikian pula dari beberapa lembaga dakwah, baik lembaga dakwah pemerintah maunpun lembaga jemaah atau organisasi. Untuk itu, Majelis Ulama Indonesia (MUI) sendiri, sebagaimana penyampaian bapak Muhammad Ilyas yang merupakan kepala Desa Baruga bahwa untuk jadwal khotbah Jumat di semua masjid Desa Baruga beserta dusun-dusunnya, semua dikelola oleh MUI Kecamatan Bantimurung.

\section{Dakwah Umum}

Dakwah Umum atau biasa juga disebut dakwah ammah merupakan jenis dakwah yang dilakukan oleh seseorang dengan media lisan yang ditujukan kepada orang banyak dengan maksud menanamkan pengaruh kepada mereka. Media yang biasa dipakai adalah berbentuk khutbah, dan metode dakwah Ammah biasa dilakukan oleh perorangan dan ada juga yang dilakukan oleh lembaga dakwah atau jemaah dakwah.

Dakwah ammah berupaya untuk membumikan nilai-nilai Islami dalam semua lini kehidupan, baik pada tataran individu, keluarga, masyarakat, maupun umat dan bangsa. Sentuhan dakwah umum pada masyarakat Desa Baruga begitu sangat dirasakan oleh warga terutama yang dilakukan oleh empat lembaga dakwah di Desa Baruga yaitu MUI Maros, Hidayatullah, DDI Mangkoso Barru dan Wahdah Islamiyah. Dari beberapa wawancara langsung kepada warga, kehadiran empat lembaga dakwah ini sangat berperan dalam penanaman nilai-nilai Islami dalam kehidupan pribadi, keluarga dan masyarakat. Dari wawancara tentang empat lembaga tersebut, seperti peran dakwah umum MUI, seorang warga yang bernama bapak Syarifuddin ${ }^{23}$ mengatakan bahwa untuk khotbah Jumat di dusun-dusun yang ada di Desa Baruga sudah diatur oleh MUI Maros, demikian pula untuk ceramah tarwih Ramadan, masjidmasjid di Desa Baruga juga bekerjasama dengan Pesantren Darul Ulum Tukamasea. Demikian pula apa yang dikatakan oleh bapak Ismail ${ }^{24}$ bahwa selain dakwah umum yang banyak dirasakan oleh kaum laki-laki, maka tidak ketinggalan kaum perempuan Desa Baruga juga aktif mengikuti agenda kegiatan dakwah terutama majlis taklim khusus ibu-ibu, berupa ceramah dan termasuk didalamnya mempelajari baca al-

\footnotetext{
${ }^{21}$ Muhammad Ilyas (52 Thn), Kepala Desa Baruga, Wawancara 28 Feb 2020, 09.24 WITA

${ }^{22}$ Organisasi Islam yang lahir di sulawesi selatan pada 18 juni 1988 dengan nama yayasan fathul muin dan menjadi organisasi massa pada 14 april 2002 dengan nama wahdah islamiyah (WI).

${ }^{23}$ Umur 35 tahun, Guru SD dan pengurus Masjid Miftahul Mu'minin, wawancara hari jumat, pukul 17.45, di dusun balang baruga maros.

${ }^{24}$ Ismail (49 Thn), Petani dan mebel, Dusun Cambajawa Desa Baruga, Wawancara 28 Februari, hari Jum'at, Pukul 17.00.
} 
Qur'an, dan juga ada halakah Dirosah khusus ibu-ibu. ${ }^{25}$

\section{Dakwah Khusus}

Dakwah khusus adalah ajakan kepada orang perorang secara langsung, ${ }^{26}$ baik itu dengan nasehat lisan secara langsung, atau nasehat secara tidak langsung dengan melalui perantara surat biasa, ataupun surat melalui SMS (short message service) atau melalui aplikasi whats app pada smartphone, atau telpon langsung, atau datang kepada seseorang dan duduk di depannya untuk menasehatinya jikalau ada hal yang perlu untuk disampaikan. ${ }^{27}$ Kegiatan dakwah khusus di Desa Baruga dan di tempat lainnya tentu bisa dilakukan oleh siapa pun, karena dakwah seperti ini siapapun bisa melakukannya lantaran tidak harus membutuhkan ilmu yang banyak. Adapun dakwah khusus adalah metode yang terbaik dan cocok untuk orang-orang yang memiliki jabatan atau sebagai pemimpin. ${ }^{28}$ Salah satu contoh hasil dari dakwah khusus yang ada di Kecamatan Bantimurung tepatnya di Desa Baruga, yaitu keberadaan bapak Asrul Rifai Rahman, S.STP., yang menjabat sebagai bapak camat di Kecamatan Bantimurung. Penulis sendiri berkesempatan bertemu langsung sebanyak dua kali, dan mendengar secara langsung bahwa beliau bersama istrinya senantiasa mengikuti kegiatan halakah tarbiyah, yaitu sebuah kegiatan belajar Islam yang dilakukan secara rutin satu kali dalam sepekan dengan kegiatan berupa perbaikan bacaan al-Qur'an (tahsinul qira'ah), pembacaan buku Islam dan penyampaian nasehat agama.

\section{Implikasi Ajaran Islam pada Kemakmuran, Keamanan dan ketentraman Masyarakat Desa Baruga}

Kehidupan masyarakat Desa Baruga dengan nilai-nilai keislamannya menjadi satu bagian terpenting yang telah membawa kepada kehidupan yang sukses, makmur, aman dan tentram. Allah Ta'ala berfirman dalam Q.S. al-A'raf/7: 96,

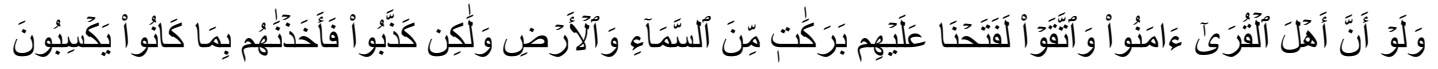

Artinya:

"Jikalau sekiranya penduduk negeri-negeri beriman dan bertakwa, pastilah Kami akan melimpahkan kepada mereka berkah dari langit dan bumi, tetapi mereka mendustakan ayat-ayat Kami itu, maka Kami siksa mereka disebabkan perbuatannya"

Ayat di atas menunjukkan bahwa keimanan dan keislaman akan membuka pintupintu keberkahan dari langit dan dari dalam bumi sebagaimana kandungan dari pada ayat

\footnotetext{
${ }^{25}$ Diroasah artinya adalah Pendidikan al-Qur'an Untuk orang dewasa, yang metodenya pertama kali diperkenalkan oleh Wahdah Islamiyah.

${ }^{26}$ Uqail al-Muqtiri>, al-Dakwah al-Fardiyyah wa Ahammiyyatuha fi $>$ Tarbiyati al-Ajya $>l$ (Cet. t.d; Saudi Arabia: Wiza>ratu al-Auqo>f, t.th), h. 3.

${ }^{27}$ Kholid ibn Muhammad al-Dubaikhi, Dali>l al-Forots wa Al-Wasa>il al-Da'wiyyah (Cet. t.d; Saudi Arabia: Wiza>ratu al-Auqo>f al-Su'u>diyyah, t.th), h. 30

${ }^{28}$ Muhammad ibn Saleh al-Usaimin, Ta'a>wun al-Dakwah wa Asaruhu fi> al-Mujtama (Cet. t.d; t.t: AlMaktabah al-Sya>milah, t.th), h. 24.
} 
tersebut di atas. Imam al-Sa'di mengatakan dalam tafsirnya bahwa: "Apabila mereka (Manusia) melaksanakan perintah Allah dengan beriman kepada Muhammad dan al-Qur'an yang hal tersebut merupakan nikmat terbesar, maka Allah akan mempercepat datangnya rezki dengan menurunkan kepada mereka hujan dan menumbuhkan tanaman."29

Nilai keimanan dan keislaman itulah yang berusaha untuk dilakukan oleh warga Desa Baruga dalam mencapai kehidupan yang sukses, makmur, aman dan tentram dan berusaha untuk menjauhi segala apa yang dilarang agama dengan meninggalkan larangan berupa adat dan budaya sedikit demi sedikit melalui sentuhan dakwah yang ada di Desa Baruga. ${ }^{30}$ Dengan demikian, kesuksesan hidup warga Baruga bisa dilihat dari hasil pertanian yang cukup untuk memenuhi kebutuhan pokok keluarga, keamanan hidup dengan sedikitnya kasus kejahatan dan ketentraman hidup dengan hidup yang rukun sesama warga. ${ }^{31}$

\section{Desa dengan Tanah Pertanian yang Subur}

Tanah yang luas dan subur serta dikelilingi gunung dan bukit menjadikan warga Desa Baruga banyak yang memilih untuk hidup dengan bertani sebagaimana desa-desa yang lain di Kecamatan Bantimurung yang telah penulis sesuaikan dengan data PDRB, ${ }^{32}$ Pemerintah Kabupaten Maros Tahun 2014. ${ }^{33}$ Sebanyak 7 kali penulis melakukan kunjungan ke Desa Baruga yang berjarak $46 \mathrm{~km}$ dari Kota Makassar, dan melihat secara langsung usaha pertanian terutama sawah yang begitu luas dan subur yang hasil usahanya dapat memenuhi kebutuhan hidup warga. Kenyataan lapangan dari usaha pertanian warga Desa Baruga bisa dikatakan telah sampai kepada usaha yang sukses, terutama bila ditinjau dari 3 (tiga) aspek kesuksesan yaitu, mengenai tujuan kerja warga Baruga yang dibangun di atas nilai-nilai Islami, keadaan hidup yang semakin baik dan berkah, serta memberikan nilai tambah pada warga/orang lain. $^{34}$

\section{Masyarakat Hidup Makmur}

Pelaksanaan nilai-nilai Islami warga Baruga telah memberikan kehidupan yang makmur dengan berlandaskan kecukupan dalam pemenuhan kebutuhan hidup. Kemakmuran ditinjau dari segi ekonomi pada hakekatnya adalah terpenuhinya kebutuhan hidup secara materil, sehingga apabila hal tersebut tidak dapat atau kurang terwujud, maka disebut miskin (kemiskinan). ${ }^{35}$ Badan Kordinasi Keluarga Berencana

\footnotetext{
${ }^{29}$ Abdurrahman al-Sa'di, Taisi $>$ r al-Kari $>m u$ al-Rahma $>n$ fi $>$ Tasi $>r$ Kala $>$ mi al-Manna $>n$ (Cet. 1; Beirut: Muassasatu al-Risa>lah, 2000 M/1420 H), h. 238.

${ }^{30}$ Haji Kamaruddin (65 Thn), Petani dan imam Masjid Miftahus Salam Samariga, Wawancara 24 Feb 2020, 14.30 WITA

${ }^{31}$ Muhammad Ilyas (52 Thn), Kepala Desa Baruga, Wawancara 28 Feb 2020, 09.24 WITA

${ }^{32}$ PDRB Adalah Singkatan Dari Produk domestik regional Bruto yang merupakan indikator penting untuk mengetahui kondisi ekonomi suatu daerah dalam periode tertentu.

${ }^{33}$ Pemerintah Kabupaten Maros, "Penyususnan RP 12-JM Tahun 2014", http://sippa.ciptakarya.pu.go.id/ (2013).

${ }^{34}$ Yanuar Fahmi, “Sukses Dalam Al-Qur'an”, Skripsi (Jakarta: Fak. Ushuluddin Syarif Hidayatullah, 2018), h. 49.

${ }^{35}$ Sudjana, "Hakikat Adil dan Makmur Sebagai Landasan Hidup Dalam Mewujudkan Ketahanan Untuk Mencapai masyarakat sejahtera melalui pembangunan nasional berdasarkan pancasila”, Ketahanan Nasional 24, no. 2 (2018): h. 141.
} 
Nasional (BKKBN) menetapkan kriteria kemiskinan yang merupakan lawan dari kemakmuran adalah: (1). Tidak dapat melaksanakan ibadah menurut agamanya, seluruh anggota keluarga tidak dapat makam dua kali sehari; (2). Seluruh anggota keluarga tidak memiliki pakain berbeda untuk di rumah, sekolah, bekerja dan bepergian; (3). Bagian terluas dari rumah berlantai tanah; (4). Tidak mampu membawa anggota keluarga ke sarana kesehatan. Dari 4 kriteria miskin tersebut, maka warga Desa Baruga sebagian besar telah sampai kepada kehidupan yang makmur. Berdasarkan hasil wawancara dengan salah seorang warga Desa Baruga Dusun Samariga, ${ }^{36}$ bahwa mereka makan tiga kali sehari dan tercukupi demikian kebutuhan pokok yang lainnya.

\section{Masyarakat Hidup Aman}

Hidup dengan rasa aman adalah sebuah karunia dan nikmat yang besar. Bahkan, kebutuhan akan hidup yang aman lebih besar dari pada kebutuhan akan rezki. Nabi Ibrahim as. dalam al-Qur'an mendahulukan meminta kehidupan yang aman dari pada rezeki. Allah Ta'ala berfirman dalam Q.S. al-Baqarah/2: 126,

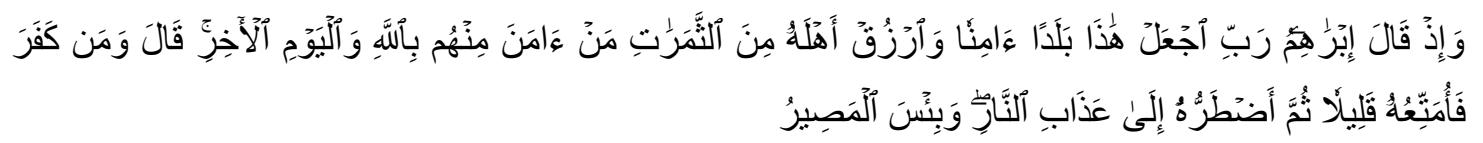

Artinya:

Dan (ingatlah), ketika Ibrahim berdoa: "Ya Tuhanku, jadikanlah negeri ini, negeri aman sentosa, dan berikanlah rezeki dari buah-buahan kepada penduduknya yang beriman di antara mereka kepada Allah dan hari kemudian. Allah berfirman: "Dan kepada orang yang kafirpun Aku beri kesenangan sementara, kemudian Aku paksa ia menjalani siksa neraka dan itulah seburuk-buruk tempat kembali."

Bahkan, para ulama menjadikan nikmat aman lebih baik dari pada nikmat sehat. Dalam kitab al-Tafsir al-Kabir dikatakan bahwa: "Sebagian ulama ditanya, apakah rasa aman lebih baik dari kesehatan? Maka jawabannya rasa aman labih baik. Dalilnya adalah seandainya kambing kakiknya patah maka akan sembuh beberapa waktu lagi, kemudian seandainya kambing diikat pada usatu tempat dekat dengan serigala, maka ia tidak akan makan sampai mati. Hal ini menunjukkah bahwa bahaya yang akibat rasa takut lebih besar daripada rasa sakit di badan."37 Ada dua faktor keamanan secara umum yang mempengaruhi kehidupan manusia yaitu: (1). Faktor lingkungan; (2). Faktor hubungan individu berupa kehidupan sosial masyarakat. ${ }^{38}$ Di Desa Baruga, kedua faktor keamanan ini yang sangat menonjol dalam kehidupan bermasyarakat warga Baruga. Hal inilah yang memberikan pengaruh keamanan yang baik pada lingkungan desa baruga. Menurut hasil wawancara dengan beberapa warga di

${ }^{36}$ Haji Kamaruddin (65 Thn), Petani dan Imam Masjid Miftahus Salam Samariga, Wawancara 24 Feb 2020, 14.30 WITA

${ }^{37}$ Fakhruddin al-Ro>dzi>, Al-Tafsi $>r$ al-Kabi $>r$, Juz 19 (Cet. 3; Beirut: Da>r Ihya>' al-Turo>ts alArabi>, 1420 H), h. 104.

${ }^{38}$ Hendi Prihanto, “Analisis Terhadap Faktor-Faktor Yang Mempengaruhi Masyarakat Untuk Menabung di Bank Syariah”, Provita 10, no. 1 (2017): h. 13. 
antaranya adalah bapak Muhammad Ilyas tentang keadaan lingkungan beliau, dan mengatakan bahwa suasana lingkungan sangat dipengaruhi oleh keberadaan dua pesantren di Desa Baruga, yakni Pesantren Darul Ulum (secara administratif, masuk Desa Tukamasea) tapi akses jalan lebih dekat ke Desa Baruga dan Yayasan AsSakinah. ${ }^{39}$ Demikian pula apa yang dikatakan oleh bapak haji Hasir tentang kehadiran dakwah dari Pesantren Mangkoso Barru dan dakwah dari Pesantren Hidayatullah, ${ }^{40}$ sangat memberikan pengaruh baiknya lingkungan yang menjadikan Desa Baruga menjadi desa yang aman.

\section{Masyarakat Hidup Tentram}

Ketentraman adalah perasaan jiwa seseorang yang dibarengi dengan rasa rida ketika mampu menggabungkan antara kemaslahatan dunianya dan kemaslahatan akhiratnya sesuai dan sejalan dengan aturan dan perintah Islam. ${ }^{41}$ Ada beberapa faktor yang mempengaruhi kehidupan tentram dalam suatu masyarakat, di antaranya adalah faktor agama, kehidupan sosial, budaya, pekerjaan dan kesehatan. ${ }^{42}$ Peran agama dalam memberikan kehidupan yang tentram sangat besar, agamalah yang menuntun manusia agar lebih dekat kepada tuhannya, dan sebagai bimbingan untuk keluar dari kegelapan dunia, dan ketentraman tidak ada dalam garis keturunan, harta benda, tetapi ketentraman hati itu ada pada agama dan ilmu. ${ }^{43}$

Dalam kehidupan sosial bermasyarakat, suasana akan terasa tentram dengan saling bantu-membantu, atau tolong-menolong. Dalam satu hadis Rasulullah Shallallahu 'Alaihi Wasallam bersabda yang artinya: "Siapa yang menyelesaikan kesulitan seorang mukmin dari berbagai kesulitan-kesulitan dunia, niscaya Allah akan memudahkan kesulitan-kesulitannya di Hari kiamat. Dan siapa yang memudahkan orang yang sedang kesulitan niscaya akan Allah mudahkan baginya di dunia dan akhirat dan siapa yang menutupi (aib) seorang muslim Allah akan tutupi aibnya di dunia dan akhirat. Allah selalu menolong hamba-Nya selama hamba-Nya menolong saudaranya."44 Demikian pula dalam pekerjaan dan kesehatan, maka akan sangat memberikan rasa tentram pada suatu masyarakat, ketika suatu masyarakat tiap-tiap warganya bekerja dan menikmati hasil dari jerih payahnya sendiri dan setiap warga sehat di setiap pagi harinya, maka Nabi kita Shallallahu 'Alaihi Wasallam menyatakan bahwa mereka seolah telah memiliki dunia beserta isinya. Maksudnya adalah bahwa mereka adalah orang-orang yang telah merasakan ketentraman hidup. Diriwayatkan oleh Imam al-Tirmidzi rahimahullah di dalam sunannya dari Abdullah bin Muhsin alKhutami bahwa Nabi Muhammad Shallallahu 'Alaihi Wasallam bersabda yang artinya: "Barangsiapa yang pada waktu paginya merasakan ketentraman hati, sehat

\footnotetext{
${ }^{39}$ Muhammad Ilyas (52 Thn, Kepala Desa Baruga, Wawancara 28 Feb 2020, 09.24 WITA.

${ }^{40}$ Hasir (51 Thn), Mantan kades, Wirausahawan, Petani, Dusun Samariga, Wawancara 28 Februari 2020, jam 11.30 WITA.

${ }^{41}$ Abdullah Muhammad Ga>nim al-Gunaima>n, Al-Sa'a $>$ dah fi $>$ al-Mandzu>r al-Isla $>m i>$ (Cet. 1; Yaman: Da>r ibnu Hazam, 1426 H), h. 32.

${ }^{42}$ Saiful H. Radeya, “Konsep Happines dan Pengukurannya”, t.d. (t.th), h. 3-4.

${ }^{43}$ Afiful Ikhwan, "Peran Agama Sebagai Alat Utama Untuk Meraih Kebahagiaan Dunia dan Akhirat", Makalah (Ponorogo: Fak. Pendididkan Matematika Universitas Muhammadiyah, 2018), h. 11.

${ }^{44}$ Abu Daud Sulaima>n al-Sajasta>ni>, Sunan Abu Da> $>$ d (Cet. td; Beirut: Al-Maktabah al-Asriyyah, t.th), h. 287.
} 
pada jasmaninya, dia memiliki makanan untuk hari itu maka sungguh seakan dunia telah dikumpulkan untuk dirinya." ${ }^{, 5}$

Suasana tentram seperti inilah yang didapatkan dan dilihat oleh penulis di Desa Baruga, aktivitas kegiatan agama yang mewarnai dusun-dusun yang ada di Desa Baruga, mulai dari ibadah salat sampai kegiatan belajar Islam yang beragam, serta kondisi kehidupan sosial yang dibangun di atas rasa saling bantu membantu dan kegiatan kerja gotong royong dalam bertani dan berladang, demikian pula kondisi alam yang memberikan rasa sehat dan segar. Tak ayal bila masyarakat Desa Baruga hidup dalam rasa yang penuh ketentraman.

\section{KESIMPULAN}

Tujuan yang ingin dicapai dari penelitian ini adalah untuk mengetahui bagaimana korelasi kehidupan berislam masyarakat Desa Baruga dengan kehidupan yang makmur, aman dan tentram. Berdasarkan hasil penelitian ditemukan bahwa ada hubungan dan keterkaitan antara aktivitas kehidupan berislam masyarakat Desa Baruga dengan kondisi kehidupan yang makmur, aman dan tentram. Di antara kehidupan berislam yang secara langsung memiliki korelasi dengan kehidupan masyarakat Desa Baruga seperti desa yang penduduknya dengan pendapatan atau penghasilan yang baik dari pertanian yang baik, kehidupan masyarakat yang makmur dan keadaan masyarakat yang hidup aman dan tentram. Kesemuanya diperoleh dari penghayatan fenomena, kesejarahan, dan realitas hidup yang dirasakan oleh warga Desa Baruga

\footnotetext{
${ }^{45}$ Muhammad ibn I>sa al-Tirmizi>, Sunan al-Tirmizi> (Cet. 2; Mesir: Sya>rikatun al-Maktabah al-
} Ba>by al-halabi>, 1395 H), h. 574 . 


\section{DAFTAR PUSTAKA}

Al-Qur'an.

Abdullah Muhammad Ga>nim al-Gunaima>n. (1426 H) Al-Sa' $a>d a h$ fi $>a l-$ Mandzu>ral-Isla>mi $>$ (Cet. 1; Yaman: Da>r ibnu Hazam).

al-A>miri>, A. M. G. (1426 H). Al-Sa'a>dah fi> al-Mandzu>r al-Isla>mi> (Vol. 1). Yaman: Da>r Ibnu Hazam.

al-Dubaikhi>, K. i. M. (t.th). Dali>l al-Furo >s wa al-Wasa >il al-Dakwiyyah (Vol. 1). Saudi Arabia: Wiza $>$ ratu al-Auqo $>$ f al-Su'u $>$ diyyah.

al-Fu>ri, S. a.-M. (t.th). Al-Rohi $>k i$ al-Makhtu $>m$ (Vol. 1). Beirut: Da>r al-Hila>l. al-Muqtiri>, U. (t.th.). Al-Dakwah al-Fardiyyah wa Ahammiyatuha fi> Tarbiyati alAjya $>l$ (Vol. 1). Saudi Arabia: Wiza $>$ ratu al-Auqo $>$ f al-Su'u $>$ diyyah.

al-Qazawaini>, I. M. A. A. M. i. Y. (t.th). Sunan Ibnu Ma>jah (Vol. 2). t.t.: Da>r Ihya al-Kutub al-Arabi>.

al-Ro>dzi, F. (1420 H). Al--Tafsi >r al-Kabi $>r$ (Vol. 19). Beirut Da>r Ihya al-Turo>ts al-Arabi>.

al-Sa'di>, A. (2000 M/1420 H). Taisi>r al-Kari>mu al-Rahma $>n$ fi $>$ Tafsi $>r$ Kala $>$ mi al-Manna $>n$ (Vol. 1). Beirut: Muassasatu al-Risa>lah.

al-Sajasta>ni>, A. D. S. (t.th). Sunan Abu Daud (Vol. 4). Beirut: Al-Maktabah alAsriyah.

al-Tirmizi>, M. i. I. (1395). sunan al-tirmidzi> (Vol. 4). Mesir: Sya>rikatun alMaktabah al-Ba>bi al-Halabi>.

al-Usaimin, M. i. S. (t.th). Ta'a>wun al-Dakwah wa Asaruhu fi> al-Mujtama' (Vol. 1). t.t: Al-Maktabah al-Sya $>$ milah.

Aliyudin, M. (2009). Pengembangan Masyarakat Islam Dalam Sistem Dakwah Islamiyah. ilmu dakwah, 4(14), 785.

Don, S. G. d. A. G. H. (2015). Model Dakwah : Satu Analisis Teoritikal. Ulum Islamiyah, 16, 25-29.

Fahmi, Y. (1439/2018). Sukses Dalam al-Qur'an (Studi Tafsir fi Zilal al-Qur'an). Syarif Hidayatullah Jakarta, Jakarta.

Farih, A. (2016). Nahdlatul Ulama (NU) dan Kontribusinya Dalam Memperjuangkan Kemerdekaan dan Mempertahankan Negara Kesatuan Republik Indonesia (NKRI). walisongo, 24(2), 252.

Hizbullah, M. (2018). Dakwah Harakah, Radikalisme, dan Tantangannya di Indonesia. misykat al-anwar, 29(2), 12.

Ikhwan, A. (2018, 2 oktober). Peran Agama Sebagai Alat Utama Untuk Meraih Kebahagiaan Dunia dan Akhirat. Ponorogo.

Imran, A. (2015). Peranan Agama Dalam Perubahan Sosial Masyarakat. Hikmah, 2(1), $25-26$.

Jumadi. (2010). Institusi Sara' di Maros Sulawesi Selatan. attoriolong, 7(2), 36.

Maros, P. K. (2014). Struktur Ekonomi Kabupaten Maros Berdasarkan Lapangan Usaha Menurut Harga Konstan Tahun 2011-2012 (Dalam Jutaan). Retrieved from sippa.ciptakarya.pu.go.id/

Maryatin. (2014). Efektifitas Metode Ceramah Dalam Penyampaian Dakwah Islam. ilmu dakwah, 34(1), 111.

Nur, A. (2015). Maros Pada Masa DI/TII 1953-1965. (s2), Universitas Negeri Makassar, Makassar. Retrieved from http://eprints.unm.ac.id/id/eprint/3407 
Nur Aisyah, P., dan H.M Rasyid Ridha. (2018). Baraka : Basis Pertahanan DI/TII di Sulawesi Selatan (1953-1965). Pattingalloang, 5(2), 58.

Nur, M. d. M. (2017). Ragam Hias pada Makam di Komplek Mesjid Makam Turikale di Maros Sulawesi Selatan. KALPATARU, 26(1), 27. doi:10.24832/kpt.v26i1.222

Prihanto, H. (2017). Analisis Terhadap Faktor-Faktor Yang Mempengaruhi Masyarakat Untuk Menabung di Bank Syariah. provita, 10(1), 13.

Radeya, S. H. (t.th). Konsep Happines dan Pengukurannya.

Riska, dkk. (2007). Masyarakat Pedesaan dan Masyarakat Perkotaan. Jakarta.

Riwana, A. R. d. A. (2019). Peran Pesantren Dalam Dunia Pendidikan Islam di Indonesia.

Rosmawati. (2017). Makam-makam Kuno Sebagai Bukti Tamadun Islam di Kabupaten Maros, Sulawesi Selatan. 1, 7-9.

Sudjana. (2018). Hakikat Adil dan Makmur Sebagai Landasan Hidup Dalam Mewujudkan Ketahanan Untuk Mencapai masyarakat sejahtera melalui pembangunan nasional berdasarkan pancasila. Ketahanan Nasional, 24(2), 141.

Takhim, M. (2016). Sistem Ekonomi Islam dan Kesejahteraan Masyarakat. Islam dan Sosial, 10(4), 84. 